\title{
Study on the Hydro-Thermal-Mechanical Characteristics of the Lime-Soil Compaction Pile in the Forming Process
}

\author{
Fengchuan Zhang, ${ }^{1}$ Jianhua Dong $\mathbb{D},{ }^{2}$ Xiaoyu Yang $\mathbb{D}^{3},{ }^{3}$ Bo Lian, ${ }^{2}$ and Xuelang Wang ${ }^{2}$ \\ ${ }^{1}$ Tianshui Construction Management Co. Ltd., Gansu Construction Investment (Holdings) Group Co. Ltd., \\ Tianshui 741000, China \\ ${ }^{2}$ Western Centre of Disaster Mitigation in Civil Engineering Ministry of Education, Lanzhou University of Technology, \\ Lanzhou 730050, China \\ ${ }^{3}$ School of Civil Engineering, Lanzhou Institute of Technology, Lanzhou 730050, China \\ Correspondence should be addressed to Jianhua Dong; djhua512@163.com
}

Received 17 September 2021; Accepted 9 November 2021; Published 24 November 2021

Academic Editor: Bingxiang Yuan

Copyright (c) 2021 Fengchuan Zhang et al. This is an open access article distributed under the Creative Commons Attribution License, which permits unrestricted use, distribution, and reproduction in any medium, provided the original work is properly cited.

To study the effect of the lime-soil compaction pile on the collapsible loess foundation and the influence of water-heat-force characteristics on the soil during compaction, the field test of lime-soil compaction pile treatment of collapsible loess foundation is carried out. This paper monitors the process of soil temperature, water, and soil pressure change in the process of pile forming. According to the macroprocess and micromechanism of lime-soil compaction pile treatment of collapsible loess foundation, the qualitative law of water-heat-force change in the process of pile forming is obtained. Meanwhile, the influence of soil damage is introduced in the process of compaction expansion. The model of pore expansion under linear damage conditions in the plastic zone is established. The formula of radial stress distribution under damage conditions is given. The influence of different damage factors on the expansion process is analyzed.

\section{Introduction}

As a practical subject, foundation treatment is in the process of continuous development and improvement and has been paid more and more attention by engineers [1-3]. Collapsible loess is widely distributed in China, and its unique soil structure characteristics and engineering performance bring some difficulties to engineering construction [4]. As a collapsible loess foundation treatment method, lime-soil compaction pile has been widely used in loess areas of Northwest China due to its advantages of local materials, in situ treatment, deep densification, and low cost [5].

Lime-soil compaction pile is to form a hole on the foundation to be treated using pipe sinking, impact, or explosive expansion, fill the hole with lime soil, and use a high-kinetic-energy rammer to squeeze and tamp the lime soil, forcing the soil around the pile to deform laterally. The porosity ratio of soil around the pile decreases, and the compactness increases. When the soil is compacted to a certain dry density or compaction coefficient, loess collapsibility can be eliminated. In the process of pile sinking and hole forming, the composite foundation formed by soil replacement, compaction, expansion, and cementation can improve the foundation bearing capacity and deformation characteristics. At present, many scholars have done a lot of research studies and discussion on the application of the lime-soil compaction pile in the treatment of collapsible loess foundation, and many results were developed. Fattah et al. [6] used the mixture of silica fume and lime-silica fume to stabilize dune soil in Iraq and studied their effects on dunes. Lime-silica fume can improve the cohesion and internal friction angle of soil. Fattah et al. [7] further studied the influence of the gypsum content on soil, and gypsum can improve the compressibility of soil. Lime can improve the properties of soil [8], can enhance the strength of soil, and is friendly to the environment. These research results of lime 
improving soil provide positive guidance for practical engineering to a great extent. Xing et al. [9] verified that the lime-soil compaction pile method could eliminate the collapsibility of loess within the range of pile depth and a certain range under the pile end through the experimental research on various methods of subgrade reinforcement, which indicates that the method is more suitable for the treatment of deep collapsible loess. Yuan et al. [10, 11] carried out experimental and numerical research on the interaction between soil and pile, observed the displacement change of soil around the pile with transparent soil, and systematically explored the mechanism of pile-soil interaction. Wang [12] made a theoretical analysis of the effect of the lime-soil pile on the collapsible loess foundation. The help of engineering tests shows that the lime-soil compaction pile is an effective and economical method for collapsible loess foundation treatment. The reinforcement of soil with additives is an effective method. Yuan et al. [13] studied the reinforcement of granite with glass fiber and liquid-modified polyvinyl alcohol polymer, which further enriched the research on the method of improving soil. Cao [14] used the unified strength theory to study the stress of the lime-soil compaction pile, obtained the elastic solution of the hole-forming process of the lime-soil compaction pile and the elastic limit load of the hole wall when yielding, and obtained the relationship between the uniform internal pressure of the hole wall and the plastic compaction radius. Min et al. [15] studied the mechanism of lime-treated soil according to the water transfer mechanism, which pointed out that lime-treated soil can transform free water with low potential energy into bound water and water with high potential energy. Lime-soil treatment technology is also used to solve large-area collapse of soil. The test results of Zakaria et al. [16] show that lime piles can reduce the possibility of gypsum soil collapse. Liu et al. [17] studied the thermal characteristics of the quicklime $(\mathrm{CaO})$ energy pile thawing on the warm frozen soil surface and pointed out that the same life lime pile has different thawing effects on different types of frozen soil, and the expansion effect of the pile can increase the density of the soil around the quicklime pile to improve the strength of the ground. Malekpoor and Poorebrahim [18] carried out the experimental study on the functional characteristics of the lime pile in soft soil. Wang et al. [19] studied the dynamic characteristics of lime-treated expansive soil and discussed the influence of different water contents, confining pressures, vibration frequencies, and other factors on the dynamic characteristics of the soil. Okyay and Dias [20] and Kasangaki and Towhata [21] explored the mechanical properties of soil after lime treatment. Zheng et al. [22] conducted a numerical study on the composite foundation strengthened by the CFG pile and studied the bearing capacity characteristics of the lime pile under different load conditions. These studies have greatly developed the research content of lime pile and played a positive role in engineering practice and theoretical research.

At present, the research of the lime-soil compaction pile for a collapsible loess foundation mainly focuses on its application effect and bearing and deformation mechanisms. However, it does not analyze the water seepage, heat transfer, mass transfer, and deformation in the lime-soil compaction pile from the micromechanism. In addition, it is generally believed that the improvement of the bearing capacity between piles is due to the water absorption and expansion of the soil between piles in the process of pile forming, and the blocking effect of granular materials under vertical load is not considered. To sum up, in order to accurately evaluate the effect of the lime-soil compaction pile of foundation soil and study the bearing mechanism of soil between piles, this paper will monitor the change of waterheat-force in the process of lime-soil compaction pile forming and carry out vertical bearing capacity static load test and plate load test on the natural site, lime-soil pile, pileside soil, and soil between piles, respectively.

\section{Materials and Methods}

By monitoring the soil temperature, moisture, soil pressure, and lateral expansion displacement of the lime-soil compaction pile, the qualitative law of water-heat-force change in the lime-soil compaction pile is obtained. The static load tests of the lime-soil pile, natural soil, soil between piles, and soil beside piles are carried out to evaluate the reinforcement effect of the lime-soil pile in the treatment of collapsible loess foundation to provide strong support for the application of the lime-soil compaction pile in the treatment of collapsible loess.

The test was carried out at the Pengjiaping Central Ecological Park project site in Qilihe Park of Lanzhou Hightech Development Zone. According to the survey data, the landform of the site is the front edge of the third terrace on the South Bank of the Yellow River. The buried depth of the groundwater level is between 19.2 and $22.4 \mathrm{~m}$ from the ground, and the soil layers are from top to bottom: (1) loesslike silt: light yellow or greyish yellow, mainly composed of silt particles, containing white calcareous nodules, with a layer thickness of $21.0 \mathrm{~m}-28.3 \mathrm{~m}$. At the place $13 \mathrm{~m}-15 \mathrm{~m}$ above the ground, it is generally in hard and hard plastic state, and the following parts are in soft plastic state or flow plastic state. (2) Pebble layer: according to the characteristics of typical river striking strata, the layer changes significantly in the north-south direction, high in the south and low in the north, with an elevation of $1543.42 \mathrm{~m}-1548.86 \mathrm{~m}$.

The length of the lime-soil compaction pile is $4 \mathrm{~m}$, the diameter of the pile is $40 \mathrm{~cm}$, the pile spacing is $1.0 \mathrm{~m}$, the pile holes are arranged according to the equilateral triangle, the lime dosage of the lime-soil pile is $9 \%-10 \%$ (weight ratio), the pile top is set with $40 \mathrm{~cm}$-thick $10 \%$ lime-soil cushion, the compaction degree of the pile body is not less than $93 \%$ (heavy compaction standard), and the compaction degree of the lime-soil cushion is not less than $97 \%$ (heavy compaction standard). The hammer weight shall not be less than $150 \mathrm{~kg}$, and the maximum diameter shall be $10 \mathrm{~cm}-16 \mathrm{~cm}$ smaller than the pile diameter. The layout of the monitoring system: after three lime-soil piles are completed, test holes are excavated (Luoyang shovel is used). In the initial state, the instrument holes are used to monitor the water content, compactness, and collapsibility of different soil layers. The probe was arranged according to the requirements of the test 
system. After the completion of three lime-soil piles, the test holes were excavated (using Luoyang shovel).

Lime-soil compaction pile is generally used to deal with collapsible loess above the groundwater level, with a treatment depth of 5-15 m. Lime soil is usually $1: 1$ (volume ratio of quicklime to site loess). The pile diameter is $400 \mathrm{~mm}$, the pile centre distance is $1200 \mathrm{~mm}$, and the pile holes are arranged in an equilateral triangle. The length of the limesoil pile is $8.0 \mathrm{~m}$, the depth of the middle monitoring hole is $7.0 \mathrm{~m}$, and the diameter is $800 \mathrm{~mm}$. The sensors are embedded at $2.0 \mathrm{~m}$ and $7.0 \mathrm{~m}$ of the monitoring hole, respectively. The field test site and construction situation are shown in Figure 1. Figure 1(a) is the mixing of lime soil, Figure 1(b) is the pile hole formed by excavation, Figure $1(\mathrm{c})$ is the image of the sensors in the hole, Figure $1(\mathrm{~d})$ is the layout of the sensors, Figure 1(e) is the actual photo of the test model after filling, and Figure 1(f) is the plan of the test model. Figure 2 is the schematic diagram of the test model.

The sensors are buried at a depth of $2.0 \mathrm{~m}$ and $7.0 \mathrm{~m}$, and the sensor layout is shown in Figure 3. A temperature and humidity sensor numbered TH1-1, TH1-2, TH1-3, and TH1-4 is arranged every $10 \mathrm{~cm}$ from pile 1 to the centre of the monitoring hole. Meanwhile, a soil pressure sensor SP1 is arranged between TH1-1 and TH1-2, and an earth pressure sensor SP2 is arranged between TH1-2 and TH1-3. The temperature and humidity sensors are placed on the connecting line between pile 2 and the circle centre of the monitoring hole. The sensor spacing is $10 \mathrm{~cm}$, and the numbers are $\mathrm{TH} 2-1, \mathrm{TH} 2-2, \mathrm{TH} 2-3$, and $\mathrm{TH} 2-4$, respectively. The temperature and humidity sensors are arranged at the exact position of pile 3, numbered TH3-1, TH3-2, TH33 , and TH3-4.

\section{Experiment Results}

Figure 4(a) shows the relationship between water content and temperature at $2 \mathrm{~m}$ of the soil beside the pile. It can be seen from the figure that the temperature showed an upward trend from April 21 to July 27, while the soil water content remained basically unchanged. The main reason is that, in the early stage of pile forming, the lime-soil pile interacts with a minimal amount of water in the surrounding soil, and the water content in the soil is basically unchanged. With the weather getting warmer, the soil temperature rises with the rise of atmospheric temperature. From July 27 to September 13 , the moisture in the soil presents a rising trend in fluctuation, and the soil temperature first increases and then decreases. The main reason is that the lime-soil pile begins to absorb water and release heat during this period, which leads to the decrease of soil moisture and the rise of soil temperature. The equation of the chemical reaction in lime is shown as follows:

$$
\mathrm{CaO}+\mathrm{H}_{2} \mathrm{O} \longrightarrow \mathrm{Ca}(\mathrm{OH})_{2}+\frac{65 \cdot 24 \mathrm{~kJ}}{\mathrm{~mol}} \text {. }
$$

However, due to more precipitation in August and September in the test area, with the infiltration of precipitation, the water absorption of the lime-soil pile works together, the water content of soil fluctuates, and the cooling caused by precipitation is more vital than that caused by lime water absorption and heat release, so the soil temperature shows a downward trend. On September 13, due to artificial water injection, the water content increased sharply, the lime-soil pile absorbed water and released heat further, the soil temperature had a rising trend, and the heat generated by lime-absorbed water made water in the soil vaporize, resulting in the decrease of the soil water content again. Figure 4(b) shows the relationship between water content and temperature at $7 \mathrm{~m}$ of the soil beside the pile. From April 26 to September 13, the lime-soil pile had little interaction with water, and the soil water content changed little. The results show that the temperature first decreases and then increases. The first decrease of temperature is caused by the gradual loss of heat generated in the pile-forming process, and the later increase of soil temperature is caused by the water absorption and heat release of the lime-soil pile. On September 13, the artificial water injection led to the rapid increase of the soil moisture content. The lime-soil pile absorbed much water and released much heat, increasing soil temperature.

Figure 5 shows the relationship between water and soil pressure at $2 \mathrm{~m}$ and $7 \mathrm{~m}$ of the soil beside the pile. From April 26 to September 13, the soil water content changed little, indicating that the lime-soil pile at this position has little effect on water. Artificial water injection on September 13 resulted in a sharp increase in the soil moisture content and a sharp decrease in soil pressure due to soil softening. This phenomenon is reflected at a depth of $2 \mathrm{~m}$ and $7 \mathrm{~m}$. After water injection, soil softening leads to a decrease in lateral earth pressure, while the chemical reaction of quicklime with water will consume part of water. With the progress of the response, the water content will decrease, and the amplitude of lateral soil pressure will increase.

The hydration process of lime is accompanied by strong water absorption and heat release. When $1 \mathrm{~kg}$ quicklime is hydrated, it generally absorbs $0.8-1.0 \mathrm{~kg}$ water, in which hydration absorbs $0.321 \mathrm{~kg}$, other water is evaporated, and $1172 \mathrm{~kJ}$ heat is released. This heat can increase the temperature of the foundation soil and make the soil produce a particular phenomenon of evaporation dehydration. The water absorption of quicklime reduces the water content of foundation soil, and the volume expansion of quicklime is nearly two times when it is hydrated, which can produce a huge squeezing force on the loose foundation soil between piles, increase the compactness of soil between piles, and improve the bearing capacity. In the process of lime hydration, the solubility of $\mathrm{Ca}(\mathrm{OH})_{2}$ in water decreases with the increase of temperature. At this time, $\mathrm{Ca}(\mathrm{OH})_{2}$ precipitates due to supersaturation and forms crystals after recrystallization, which makes it compact and has high strength. Due to the interaction between positively charged calcium ions and negatively charged clay particles in $\mathrm{Ca}(\mathrm{OH})_{2}$, colloidal condensation is formed. With the increase of lime-soil age, the solidification of soil increases, and the strength of soil gradually increases. $\mathrm{Ca}(\mathrm{OH})_{2}$ around the pile contacts the air to form $\mathrm{CaCO}_{3}$. The crystallization of $\mathrm{CaCO}_{3}$ is combined with the crystallization of $\mathrm{Ca}(\mathrm{OH})_{2}$ (carbonization), which makes the hard- 


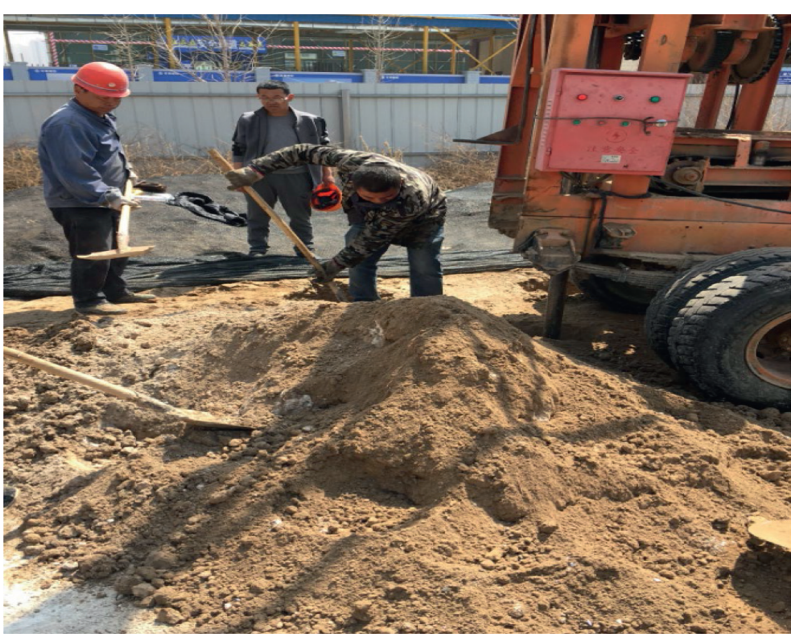

(a)

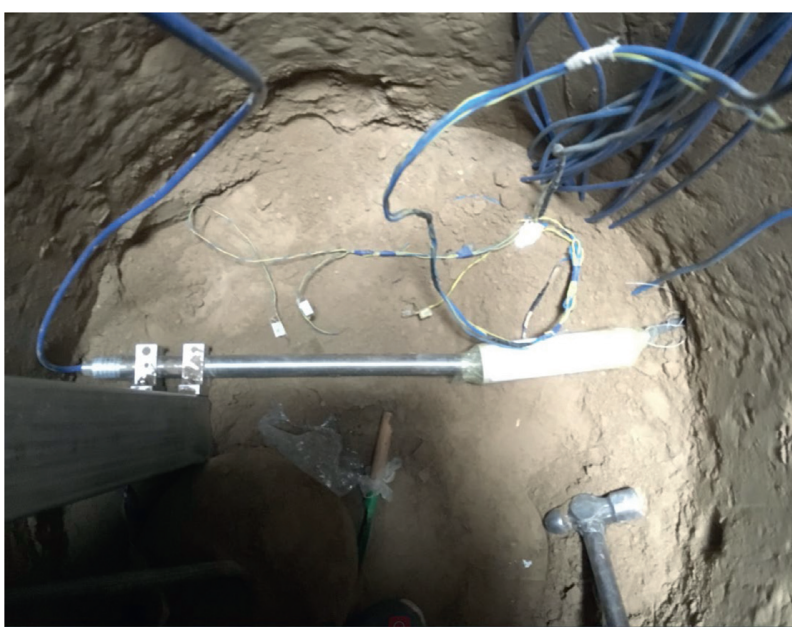

(c)

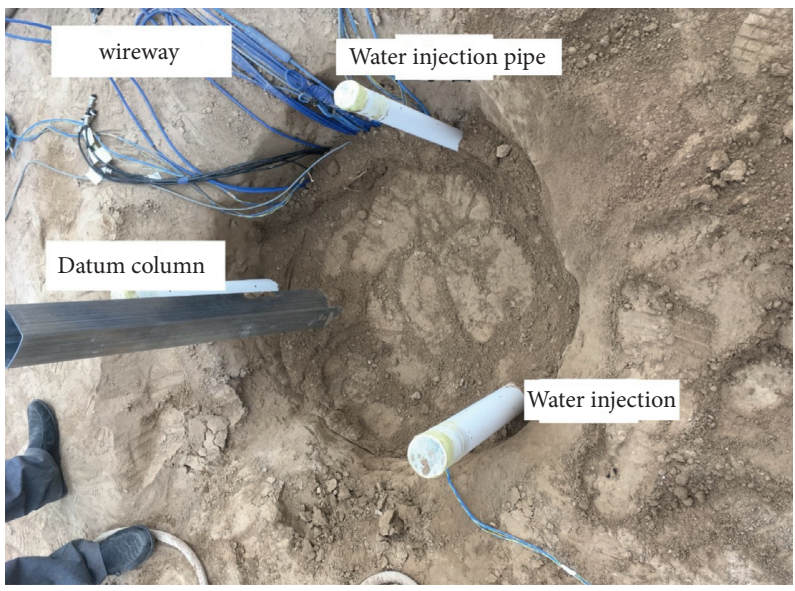

(e)

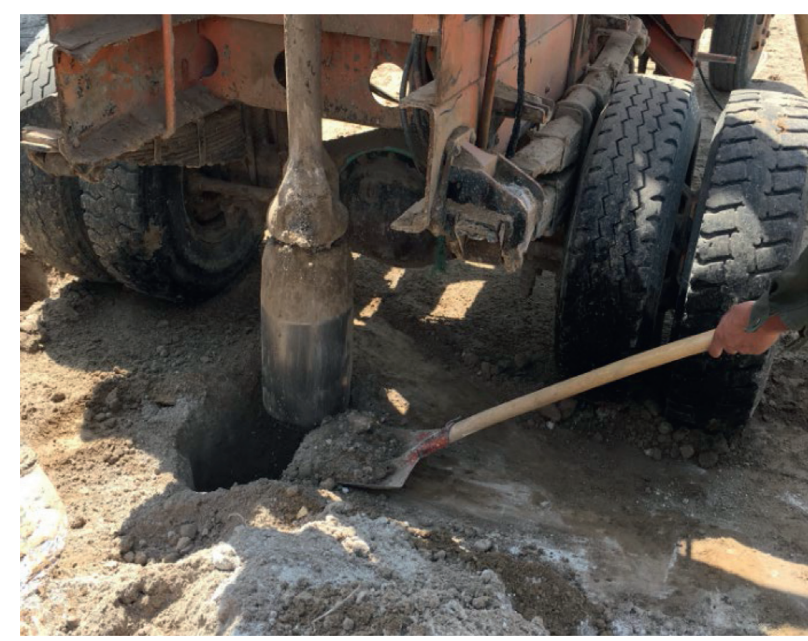

(b)

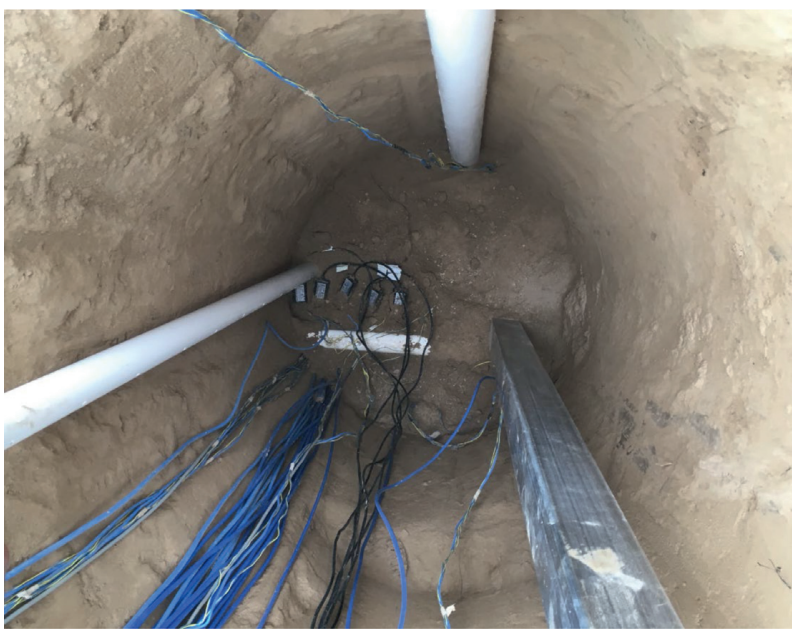

(d)

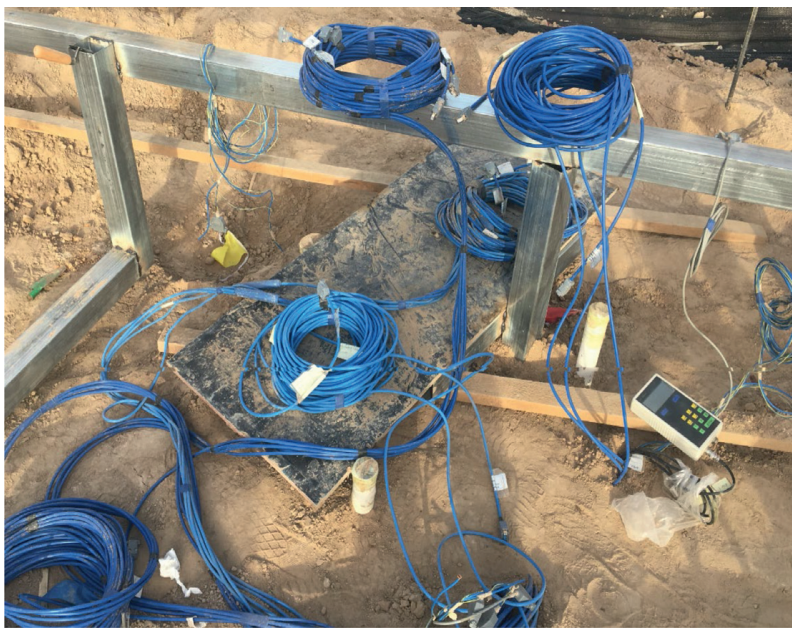

(f)

Figure 1: The field test. (a) Mixing lime soil. (b) Lime soil by using the hammer. (c) Sensor in the hole. (d) Sensor layout. (e) Layout plan of the pile top. (f) Test site after levelling. 


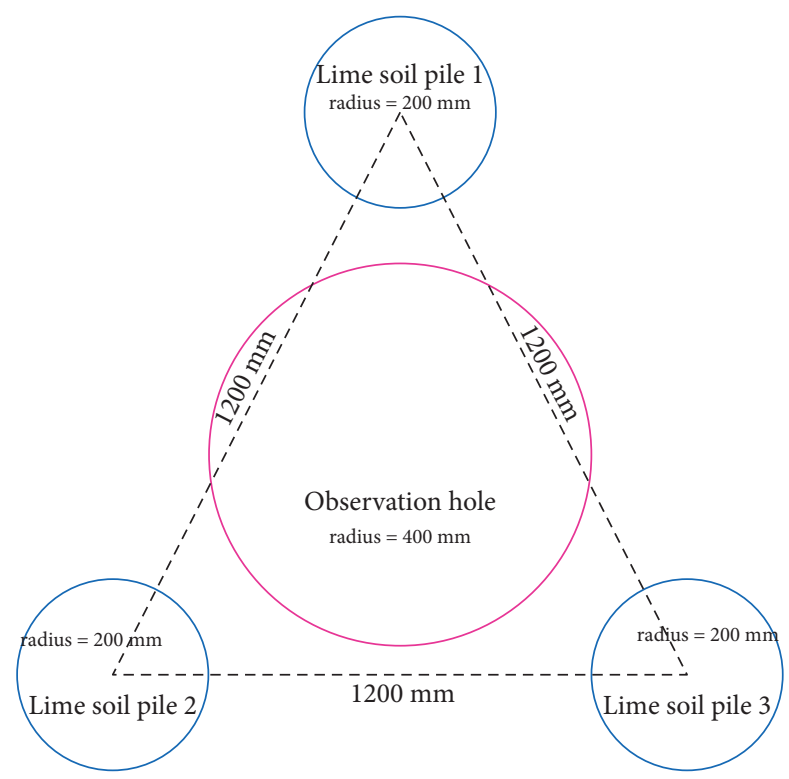

FIGURE 2: Schematic diagram of the test model.

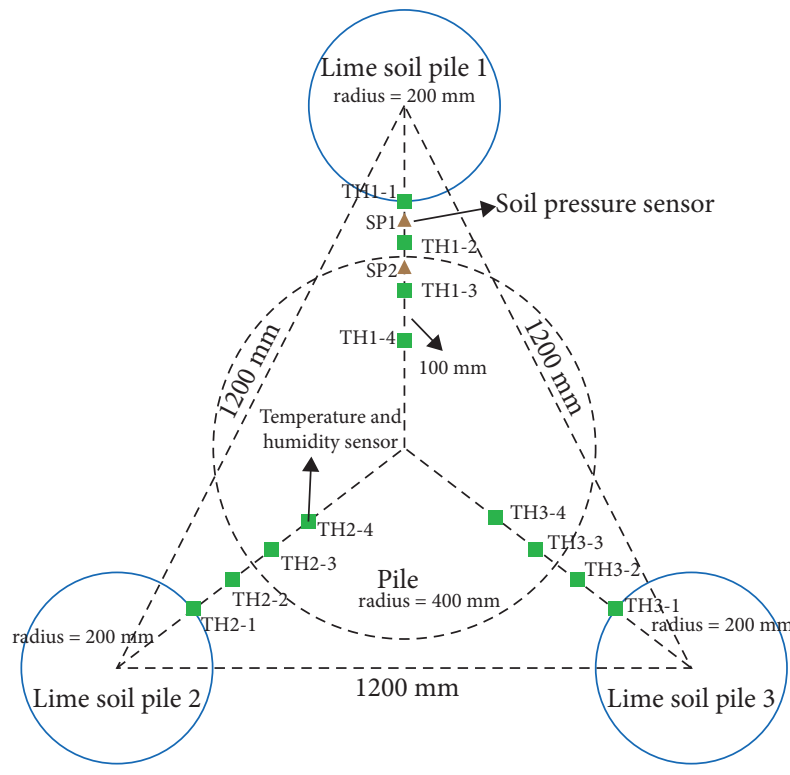

Figure 3: Sensor layout diagram.

shell layer with high strength form around the pile, improves the mechanical properties of the foundation soil, and improves the bearing capacity of the foundation. In the lime-soil compaction pile foundation, because the deformation modulus of the lime-soil pile is much larger than that of the soil between the piles, the load produces stress concentration on the pile, which reduces the stress in the soil at a certain depth below the bottom of the foundation and eliminates the unfavourable factors of a large number of compression deformation and collapsible deformation in the bearing layer. In addition, the lateral restraint effect of the lime-soil pile on the soil between piles can limit the lateral movement of the soil, and the soil between piles only produces vertical compaction, which makes the pressure and settlement in a linear relationship.

\section{Theoretical Analysis of the Expansion Process}

The radial pressure produced in the expansion process of the lime-soil pile can produce a compaction effect on soil, which can be analyzed by column hole expansion theory. The stress, strain, and other variables are only functions of the radial coordinate $r$. The calculation model is shown in Figure 6.

The elastic stage satisfies the static equilibrium differential equation, as shown in the following:

$$
\frac{\mathrm{d} \sigma_{r}}{\mathrm{~d} r}+\frac{\sigma_{r}-\sigma_{\theta}}{r}=0,
$$

where $\sigma_{r}$ is the radial stress, $\sigma_{\theta}$ is the circumferential stress, and $r$ is the radial coordinate in the polar coordinate system.

The geometric equation is shown as follows:

$$
\begin{gathered}
\varepsilon_{r}=-\frac{\mathrm{d} u_{r}}{\mathrm{~d} r}, \\
\varepsilon_{\theta}=-\frac{u_{r}}{r},
\end{gathered}
$$

where $u_{r}$ is the radial displacement, $u_{\theta}$ is the circumferential displacement, $\varepsilon_{r}$ is the radial strain, and $\varepsilon_{\theta}$ is the circumferential strain.

This problem was originally an axisymmetric plane strain problem. In order to simplify the calculation, we can first calculate it according to the plane stress problem and then get the solution of plane strain through the transformation of $\mu$ and $E$. The physical equation of the plane stress problem satisfies Hooke's law, as shown in the following: 


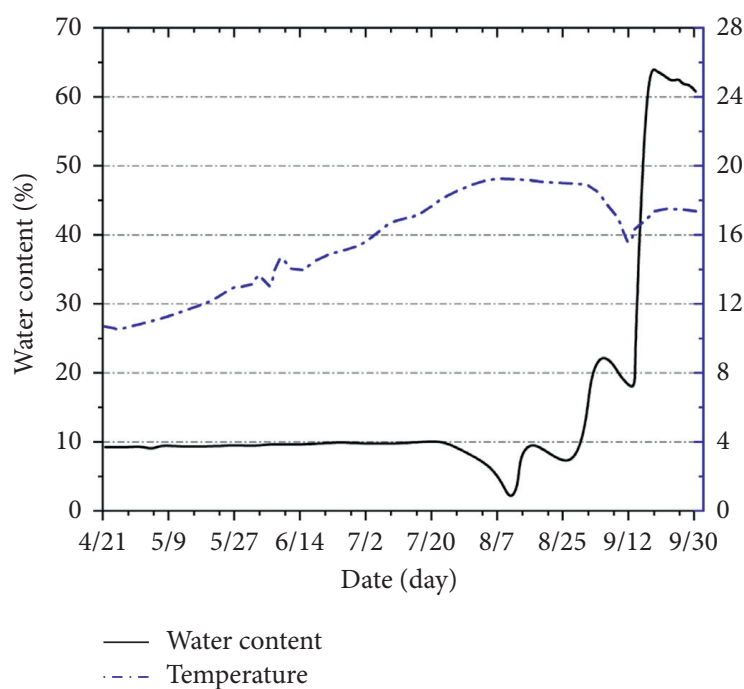

(a)

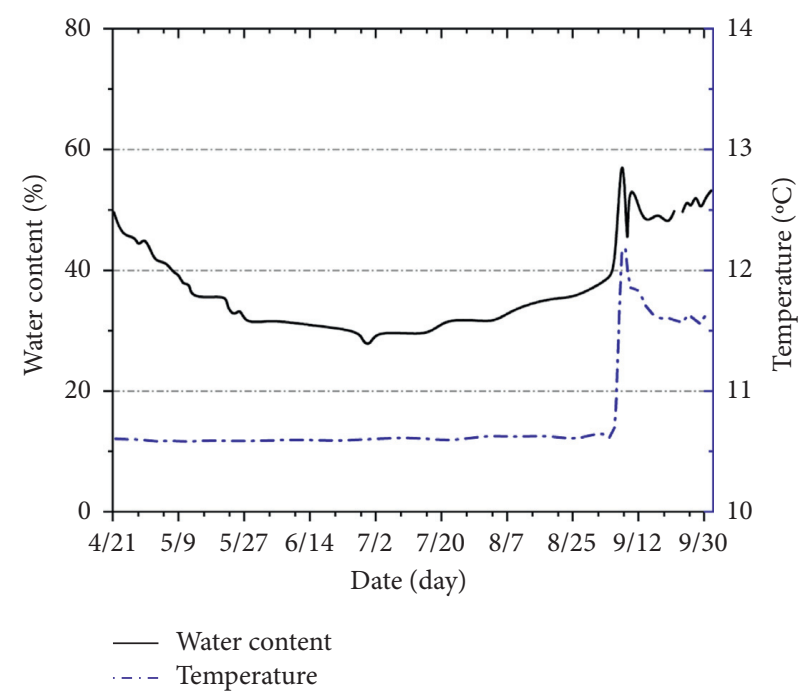

(b)

Figure 4: Temperature and moisture curve. (a) At $2 \mathrm{~m}$ depth. (b) At $7 \mathrm{~m}$ depth.

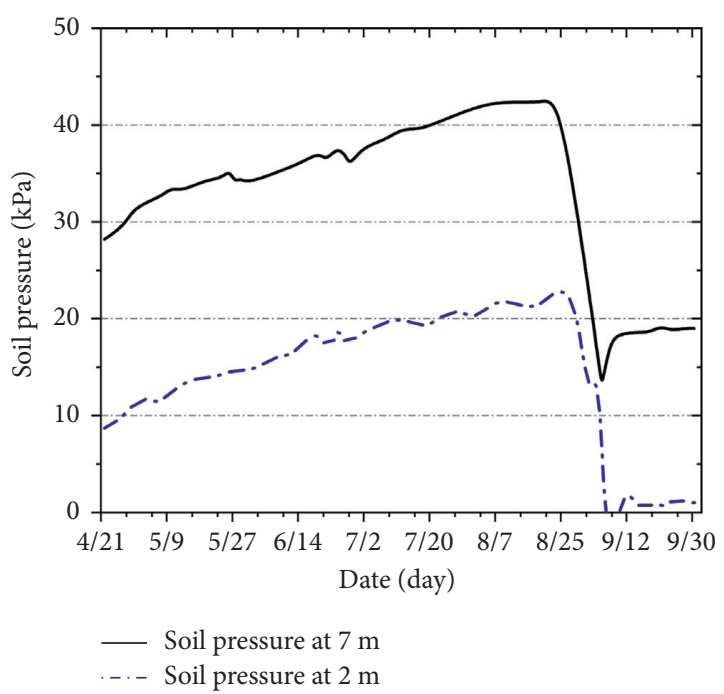

FIGURE 5: Soil pressure curve.

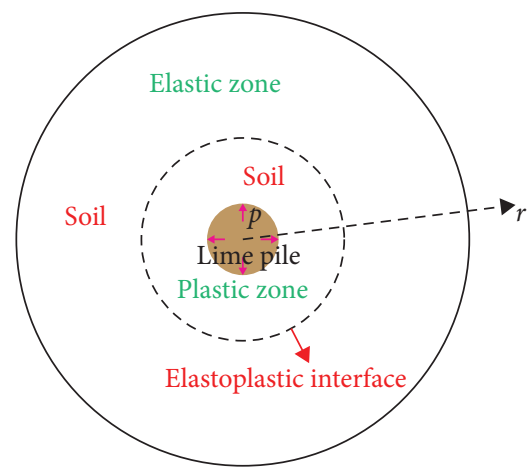

FIGURE 6: The model of column hole expansion.

$$
\begin{aligned}
& \varepsilon_{r}=\frac{1}{E}\left(\sigma_{r}-\mu \sigma_{\theta}\right), \\
& \varepsilon_{\theta}=\frac{1}{E}\left(-\mu \sigma_{r}+\sigma_{\theta}\right),
\end{aligned}
$$

where $E$ is the elastic modulus of soil and $\mu$ is Poisson's ratio of soil.

When the soil is in the elastic stage, the above three equations can be used to complete the solution. According to the stress solution method, the deformation compatibility equation expressed by the strain can be obtained from geometric equation (3):

$$
\frac{\mathrm{d} \varepsilon_{\theta}}{\mathrm{d} r}+\frac{\varepsilon_{\theta}-\varepsilon_{r}}{r}=0
$$

By introducing the physical equation into deformation compatibility equation (5) expressed by strain, the deformation compatibility equation expressed by the stress component can be obtained, as shown in the following:

$$
\frac{\mathrm{d} \sigma_{\theta}}{\mathrm{d} r}-\mu \frac{\mathrm{d} \sigma_{r}}{\mathrm{~d} r}+\frac{1+\mu}{r}\left(\sigma_{\theta}-\sigma_{r}\right)=0 .
$$

From equilibrium differential equations (2) and (6), the equation about the radial stress second-order ordinary differential equation is established:

$$
\frac{\mathrm{d}^{2} \sigma_{r}}{\mathrm{~d} r^{2}} r+3 \frac{\mathrm{d} \sigma_{r}}{\mathrm{~d} r}=0
$$

At the initial radius $r_{0}$, the radial stress at the hole wall is the expansion pressure $p$. When the radius tends to be infinite, the stress change caused by additional stress tends to 0 , and there is $r \longrightarrow \infty: \sigma_{r}=0$. The inner stress of the elastic zone is 


$$
\sigma_{r}=p\left(\frac{r_{0}}{r}\right)^{2}
$$

The circumferential stress can be expressed as follows:

$$
\sigma_{\theta}=-p\left(\frac{r_{0}}{r}\right)^{2}
$$

At this time, the radial displacement of soil in the elastic zone is

$$
u_{r}=-\varepsilon_{\theta} r=\frac{1+\mu}{E} p \frac{r_{0}^{2}}{r}
$$

Classical Vesic's [23] theory does not consider the structural changes of soil caused by a disturbance in the process of expansion. After water injection, the soil is nearly saturated and disturbed by external forces. The external influence in the process of expansion will cause the structural changes of soil to be disturbed and reduce the strength of the soil. Based on this idea, the failure of the soil belongs to the category of strength theory. Therefore, it has a specific practical significance to consider the influence of damage on soil in the plastic zone.

When $\omega=0$, the disturbance effect is 0 , and the strength of soil is not affected at all. When $\omega=1$, it means that the soil is significantly disturbed, and the strength loss of soil is $100 \%$; then, the maximum disturbance occurs at the hole wall, where the undrained strength of soil can be modified to $\omega \cdot C_{u}$. The degree of disturbance is set to decrease linearly along the radial direction. Because the soil outside the plastic zone is in an elastic state and does not yield, it is considered that the site is not disturbed, and the soil strength in the elastic zone is still $C_{u}$. Therefore, the strength of soil at the radius of the plastic zone $r_{p}$ returns to an undisturbed state, that is, $r=r_{p}$, and the strength is $C_{u}$. When the disturbance function is a linear model, the undrained strength of soil is as follows:

$$
\tau_{u}=C_{u}\left(1-w \cdot \frac{r_{p}-r}{r_{p}-r_{u}}\right)
$$

where $\omega$ is the damage coefficient of soil, $r_{p}$ is the radius of the plastic zone, and $r_{u}$ is the radius of the hole after expansion.

Under the undrained condition, Tresca's criterion is modified to equation (11):

$$
\sigma_{r}-\sigma_{\theta}=2 C_{u}\left(1-\omega \cdot \frac{r_{p}-r}{r_{p}-r_{u}}\right) \text {. }
$$

According to equation (12) and equilibrium differential equation (2), the governing equation of radial stress under the linear damage model in the plastic zone is obtained:

$$
\frac{\mathrm{d} \sigma_{r}}{\mathrm{~d} r}=-2 C_{u}\left(1-\omega \frac{r_{p}-r}{r_{p}-r_{u}}\right) \cdot \frac{1}{r} .
$$

The governing equation is solved by the method of separating variables. The radial stress at the hole wall is $p_{u}$, and the expression of radial stress (14) is obtained:

$$
\sigma_{r}=p_{u}+\frac{2 \omega C_{u}\left(r_{u}-r\right)}{r_{p}-r_{u}}+\frac{2 C_{u}\left(\omega r_{p}-r_{p}+r_{u}\right)}{r_{p}-r_{u}} \ln \left(\frac{r}{r_{u}}\right) \text {. }
$$

Considering that, at the elastic-plastic interface, the stress can meet both elastic and plastic solutions, thus, the ultimate expansion pressure is obtained:

$$
p_{u}=C_{u}(1+2 \omega)+\frac{2 C_{u}\left(\omega r_{p}-r_{p}+r_{u}\right)}{r_{p}-r_{u}} \ln \left(\frac{r_{u}}{r_{p}}\right) \text {. }
$$

The expression of radial stress and circumferential stress in the plastic region is obtained as follows:

$$
\begin{aligned}
\sigma_{r}= & C_{u}(1+2 \omega)+\frac{2 \omega C_{u}\left(r_{u}-r\right)}{r_{p}-r_{u}} \\
& +\frac{2 C_{u}\left(\omega r_{p}-r_{p}+r_{u}\right)}{r_{p}-r_{u}} \ln \left(\frac{r}{r_{p}}\right), \\
\sigma_{\theta}= & C_{u}(2 \omega-1)+\frac{2 C_{u} \omega\left(r_{p}+r_{u}-2 r\right)}{r_{p}-r_{u}} \\
& +\frac{2 C_{u}\left(\omega r_{p}-r_{p}+r_{u}\right)}{r_{p}-r_{u}} \ln \left(\frac{r}{r_{p}}\right) .
\end{aligned}
$$

In order to explore the characteristics of the expansion process, a numerical example is carried out. The elastic modulus of the soil is $2000 \mathrm{kPa}$, and the damage coefficient $\omega$ varies from 0.0 to 1.0 , and when $\omega=0$, the yield criterion degenerates to the classical Tresca criterion. Under the undrained condition, Poisson's ratio $\mu$ is 0.5 , the radius of the expanded hole is $0.2 \mathrm{~m}$, and the undrained strength of soil $C_{u}$ is $20 \mathrm{kPa}$. Under different damage coefficients, the radial stress distribution of the expanded soil is shown in Figure 7. In Figure 7, since the damage only occurs in the plastic zone of the soil, the results are consistent in the elastic zone. When the damage coefficient $\omega=0$, it is equivalent to the result of Vesic's solution. There is no strength damage in the plastic zone, and the radial stress $\sigma_{r}$ at the hole wall is the largest; the value is $90.13 \mathrm{kPa}$. With the increase of damage coefficient $\omega$, the extreme value of radial stress decreases; when $\omega=0.2,0.4,0.6,0.8$, and 1.0 , the radial stress at the hole wall is $81.17 \mathrm{kPa}, 72.20 \mathrm{kPa}, 63.24 \mathrm{kPa}, 54.27 \mathrm{kPa}$, and $45.31 \mathrm{kPa}$, respectively. The distribution of the radial stress in the plastic zone is shown in Figure 8. The increase of the damage coefficient leads to the decrease of the radial stress amplitude. Considering the damaging effect, the maximum variation of the radial stress reaches $49.73 \%$. If the influence of soil damage is ignored, the calculation result will be too large, and the compaction effect of the lime-soil pile will be overestimated, which is unfavourable to the project. 


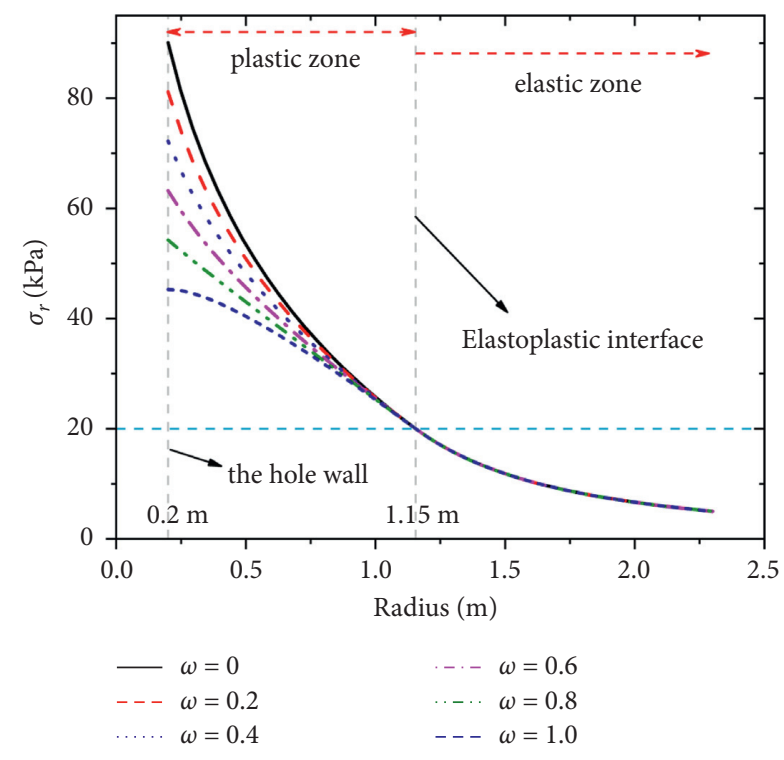

Figure 7: Radial stress distribution.

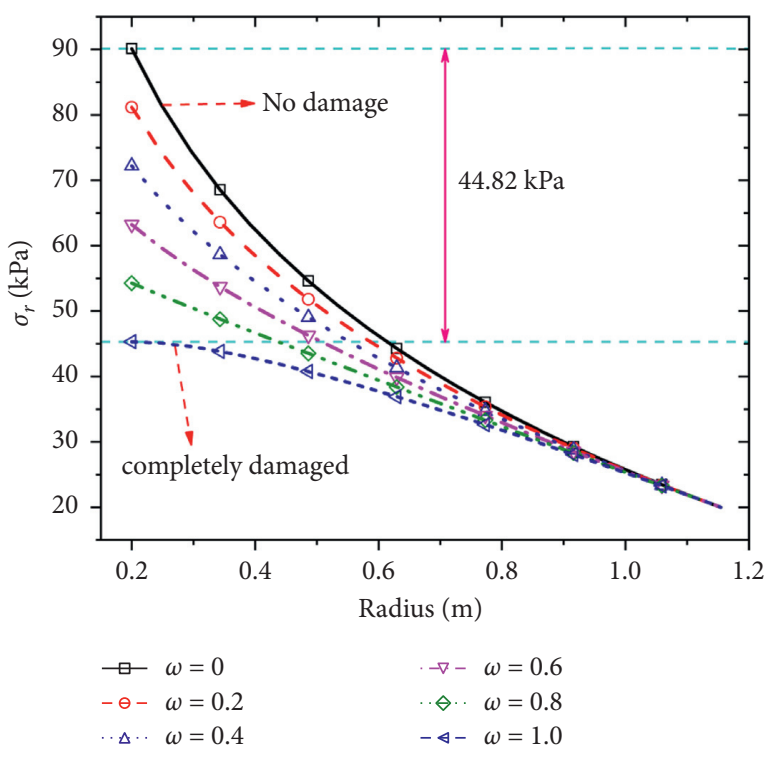

Figure 8: Radial stress distribution in the plastic zone.

\section{Conclusions}

The hydration reaction of lime in lime-soil piles with water will release a lot of heat, and the volume of lime will expand significantly. Therefore, the increase of the soil water content will lead to an increase in soil temperature and earth pressure. When the soil water content increases sharply, the soil beside the pile will soften, which will lead to a sharp decrease of the earth pressure in a short time. Then, due to the gradual development of the hydration reaction of the lime-soil pile, pile expansion will cause the increase of soil pressure. Considering the damaging effect of construction disturbance on the soil structure, the strength of the soil in the plastic zone changes linearly along the radial direction. The expansion calculation results under the linear damage model are lower than classical Vesic's result. Different damage coefficients will lead to varying degrees of reduction of the radial stress, and the maximum variation range is $49.73 \%$.

\section{Data Availability}

The data used to support the findings of this study are available from the corresponding author upon request.

\section{Conflicts of Interest}

The authors declare that they have no conflicts of interest regarding the publication of this paper.

\section{Acknowledgments}

This study was supported by the Top Ten Science and Technology Innovation Projects in Lanzhou (no. 2020-2-11), Lanzhou Talent Innovation and Entrepreneurship Project (no. 2017-RC-85), High-Value Patent Cultivation and Transformation Project of Gansu Intellectual Property Office (no. 20ZSCQ034), and Gansu Basic Research Innovation Group Project (no. 20JR10RA205).

\section{References}

[1] Z. Liu, Loess Mechanics and Engineering, Shaanxi Science and Technology Press, Xi'an, China, 1997.

[2] X. Ding-yi, "Mechanical properties and application of loess study of past, present and future," Journal of Underground Space, vol. 19, no. 4, pp. 274-283, 1999.

[3] G. Gao, "Loess soil deformation and structure theory," Journal of Geotechnical Engineering, vol. 12, no. 4, pp. 1-9, 1990.

[4] W. Xuelang and Y. Zhu, "Theoretical analysis and test of the foundation of collapsible loess reinforced by lime piles," Journal of Xian University of Architecture and Technology, vol. 42, no. 2, pp. 288-293, 2010.

[5] G. Ye and Y. Gao, Foundation Treatment, China Construction Industry Press, Beijing, China, 3rd edition, 2009.

[6] M. Y. Fattah, H. H. Joni, and A. Al-Dulaimy, "Strength characteristics of dune sand stabilized with lime-silica fume mix," International Journal of Pavement Engineering, vol. 19, no. 9-10, pp. 874-882, 2018.

[7] M. Y. Fattah, H. H. M. Al-Musawi, and F. A. Salman, "Treatment of collapsibility of gypseous soils by dynamic compaction," Geotechnical and Geological Engineering, vol. 30, no. 6, pp. 1369-1387, 2012.

[8] A. J. Alrubaye, M. Hasan, and M. Y. Fattah, "Engineering properties of clayey soil stabilized with lime," ARPN Journal of Engineering and Applied Sciences, vol. 11, no. 4, pp. 24342441, 2016.

[9] Y. Xing, C. Wang, L. Zhang, and S. H. Kuang, "Subgrade treatment effects for collapsibe loess subgrade of FuxinChaoyang Freeway in west of Liaoning province," Journal of Jilin University (Earth Science Edition): Earth Science Edition, vol. 38, no. 1, pp. 98-104, 2008.

[10] B. Yuan, Z. Li, Z. Su, Q. Luo, M. Chen, and Z. Zhao, "Sensitivity of multistage fill slope based on finite element model," Advances in Civil Engineering, vol. 2021, pp. 1-13, 2021.

[11] B. Yuan, Z. Li, Z. Zhao, H. Ni, Z. Su, and Z. Li, "Experimental study of displacement field of layered soils surrounding 
laterally loaded pile based on transparent soil," Journal of Soils and Sediments, vol. 21, no. 9, pp. 3072-3083, 2021.

[12] X. Wang, Study on Characteristics of Collapse Deformation for Collapsible Loess, Foundation Treatment Method and Tests, Lanzhou University of Technology, Lanzhou, China, 2012.

[13] B. Yuan, Z. Li, Y. Chen et al., "Mechanical and microstructural properties of recycling granite residual soil reinforced with glass fiber and liquid-modified polyvinyl alcohol polymer," Chemosphere, vol. 286, Article ID 131652, 2022.

[14] L. Cao, J.-h. Zhao, and W. Xue-ying, "Stress. Analysis of lime soil compacted pile based on the. Unified strength theory," Rock and Soil Mechanics, vol. 27, no. 10, pp. 1786-1790, 2006.

[15] F. Min, J. Ma, N. Zhang, H. Song, J. Du, and D. Wang, "Experimental study on lime-treated waste soil based on water transfer mechanism," KSCE Journal of Civil Engineering, vol. 25, no. 5, pp. 1645-1652, 2021.

[16] W. A. Zakaria, H. O. Abbas, and Q. A. Aljanabi, "Vertical and inclined lime injected piles under footing resting on collapsing soil," Journal of the Institution of Engineers, vol. 101, no. 3, pp. 513-521, 2020.

[17] W. Liu, L. Chen, W. Yu, Y. Lu, F. Yu, and D. Hu, "Experimental study on thermal performance of quicklime $(\mathrm{CaO})$ energy pile aimed to thaw the warm permafrost ground," Applied Thermal Engineering, vol. 156, pp. 189-195, 2019.

[18] M. R. Malekpoor and G. Poorebrahim, "Behavior of compacted lime-(well-graded) soil columns: large scale tests and numerical modelling," KSCE Journal of Civil Engineering, vol. 19, no. 4, pp. 893-903, 2015.

[19] M. Wang, L. Kong, C. Zhao, and M. Zang, "Dynamic characteristics of lime-treated expansive soil under cyclic loading," Journal of Rock Mechanics and Geotechnical Engineering, vol. 4, no. 4, pp. 352-359, 2012.

[20] U. S. Okyay and D. Dias, "Use of lime and cement treated soils as pile supported load transfer platform," Engineering Geology, vol. 114, no. 1, pp. 34-44, 2010.

[21] G. Kasangaki and I. Towhata, "Wet compaction and lime stabilization to mitigate volume change potential of swelling clayey soils," Soils and Foundations, vol. 49, no. 5, pp. 813-821, 2009.

[22] J.-J. Zheng, S. W. Abusharar, and X.-Z. Wang, "Three-dimensional nonlinear finite element modeling of composite foundation formed by CFG-lime piles," Computers and Geotechnics, vol. 35, no. 4, pp. 637-643, 2008.

[23] A. S. Vesic, "Expansion of cavities in infinite soil mass," Journal of the Soil Mechanics and Foundations Division, vol. 3, no. 98, pp. 265-298, 1973. 